\title{
Preparing for Doris: Exploring Public Responses to Impact-Based Weather Warnings in the United Kingdom $\mathscr{\theta}$
}

\author{
Andrea L. TAYlOR AND ASTRID KAUSE \\ Centre for Decision Research, Leeds University Business School, and Sustainability Research Institute, \\ School of Earth and Environment, University of Leeds, Leeds, United Kingdom \\ BARBARA SUMMERS \\ Centre for Decision Research, Leeds University Business School, Leeds, United Kingdom \\ MELANIE HARROWSMITH \\ Met Office, Exeter, United Kingdom
}

(Manuscript received 5 December 2018, in final form 9 May 2019)

\begin{abstract}
In the United Kingdom, the Met Office issues regionally calibrated impact-based weather warnings. These aim to reduce harm to people and property. To decrease risk from severe weather, it is important to understand how members of the U.K. public interpret and act on these warnings. This paper addresses this through a postevent survey $(n=552)$ conducted following Storm Doris, a 2017 winter storm during which wind warnings were issued across much of the United Kingdom. Survey questions examined 1) understanding of impact-based wind warnings, 2) interpretation of local warning level, 3) predictors of perceived local risk (likelihood, impact severity, concern) implied by warnings, 4) predictors of trust in the forecast, and 5) predictors of recalled and anticipated action. Our findings indicate that U.K. residents generally understand that weather warnings are based on potential weather impacts, although many do not realize warnings are regionally calibrated. We also find that while local warning levels are rarely underestimated, they may sometimes be overestimated. Institutional trust in the Met Office and perceived vulnerability to weather predict both perceived risk and behavioral response, while warning "understandability" is linked to greater trust in the forecast. Strikingly, while differences in local warning levels influenced risk perception, they did not affect recalled or intended behavioral response. This study highlights the importance of institutional trust in the effective communication of severe weather warnings, and a need for education on impact-based weather warnings. Above all, it demonstrates the need for further exploration of the effect of weather warnings on protective behavior.
\end{abstract}

\section{Introduction}

In the United Kingdom, severe weather poses a threat to property, infrastructure, well-being, and even lives. Through timely impact-based warnings, the Met Office's National Severe Weather Warning Service aims to inform the public, government, and decisionmakers about potential impacts from severe weather

Supplemental information related to this paper is available at the Journals Online website: https://doi.org/10.1175/WCAS-D-180132.s1.

Corresponding author: Andrea L. Taylor, a.l.taylor@leeds.ac.uk and prompt appropriate protective action. Understanding how the public responds to such warnings is important for effective service delivery. While the Met Office conducts regular postevent surveys with the public to monitor and improve the National Severe Weather Warning Service, there have to date been comparatively few peer-reviewed studies exploring responses to severe weather warnings in the United Kingdom. Addressing this gap is important for evaluating communications, and identifying where future improvements can be made. Findings from other countries where more studies exist can provide valuable insights into the factors that may affect behavioral response to severe weather warnings. However, 
these may not always transfer directly to the United Kingdom because of differences in regional climate and cultural context. In this paper we first review the literature on three key areas of evidence pertaining to weather risk communication: the interpretation of impact-based weather warnings, risk perception, and individual differences. We then start to address the lack of U.K. research by examining responses to Storm Doris, a severe winter storm that moved across the United Kingdom overnight and into the morning of 23 February 2017, bringing gusts of wind up to $94 \mathrm{mph}$ and receiving widespread coverage in mainstream and social media. We explore how the warnings were interpreted and the factors predicting recalled and anticipated responses to impact-based wind warnings.

\section{a. Interpretation of weather warnings}

\section{1) IMPACT-BASED WARNINGS}

Since 2011 the Met Office has issued impact-based warnings based on the likelihood and potential severity of negative consequences resulting from severe weather (Goldstraw 2012). This marked a departure from earlier phenomena-based warnings, which were based solely on specific meteorological thresholds being crossed (e.g., wind speed $\mathrm{mph}$, mm of precipitation). The rationale for this approach is that identical meteorological conditions may represent a more severe threat to people and property in one region than another because of differences in infrastructure, population, and hazard preparedness. For instance, in the case of the 2013 Saint Jude's storm, areas with the highest expected risk of vehicles overturning in strong winds were not those expected to have the highest wind speed (WMO 2015). In the United Kingdom, public consultations show support for impact-based warnings (Goldstraw 2012). The approach is also supported by the World Meteorological Organization (WMO 2015). Indeed, studies conducted in the United States suggest that the phrase "warning" is widely interpreted as reflecting the anticipated impacts of severe weather rather than meteorological conditions alone (Williams et al. 2017). Impact-based (vs phenomena-based) messages have also been linked to greater warning comprehension (Potter et al. 2018) and intention to undertake protective behaviors (Casteel 2016, 2018; Morss et al. 2018; Weyrich et al. 2018), although these may not always be those recommended (Ripberger et al. 2015a).

The Met Office currently issues impact-based warnings for winds, rainfall, snow, ice, thunderstorms, lightning, and fog. At the time of Storm Doris, a traffic light system, used alongside predefined action statements, denoted four levels of warning: green (since replaced by gray) = no warning, yellow $=$ be aware, amber $=$ be prepared, and red $=$ take action. While the action statements have since been discontinued and replaced by more specific guidance about how to respond to the warning, colorcoded warning levels remain. Warning levels integrate information about expected likelihood and local impact severity, using the warning impact matrix format shown in Fig. 1. This means that an amber warning could represent either higher likelihood of less severe impacts or lower likelihood of more severe impacts. Warnings are also location dependent, reflecting regional differences in vulnerability to weather impacts. That is to say that the meteorological conditions needed to trigger an amber wind warning in an area where strong winds are rare may be lower than areas where they are common and infrastructure is less vulnerable to wind damage.

The switch from phenomena-based warnings to impact-based warnings is still relatively recent. Some individuals may thus be unaware that warning thresholds differ between locations. If so, this could lead those in locations more frequently exposed to specific weather phenomena (e.g., strong winds, heavy rainfall) to discount warnings on the basis that their region is better able to cope with severe weather than others. Indeed, evidence indicates that people draw on past experience to reinterpret weather warnings. For instance, it has been consistently found that people presented with deterministic forecasts draw inferences about the uncertainty surrounding these (Morss et al. 2008; Peachey et al. 2013). This type of reinterpretation is appropriate in some contexts (e.g., inferring that uncertainty surrounds a deterministic forecast, using local knowledge to judge the threat from a phenomenabased forecast). However, where these are already accounted for it may lead to recipients making inappropriate adjustments.

\section{2) COMmunicAting LEVELS OF RISK}

Where any warning system with multiple warning levels is implemented, there is an implicit assumption that these different levels will be understood. In the United States, however, it has been found that "watch," "advisory," and "warning"- - each denoting a different status-are often conflated or misinterpreted (Donner et al. 2012; Morss et al. 2016; Ripberger et al. 2015b; Silver 2015; Williams et al. 2017). This is concerning as appropriate understanding of these terms has been linked to appropriate action (Morss et al. 2016). Color may also be used to convey levels of risk. U.S. research exploring the use of color saturation in tornado 
National Severe Weather Warnings - United Kingdom

(a)

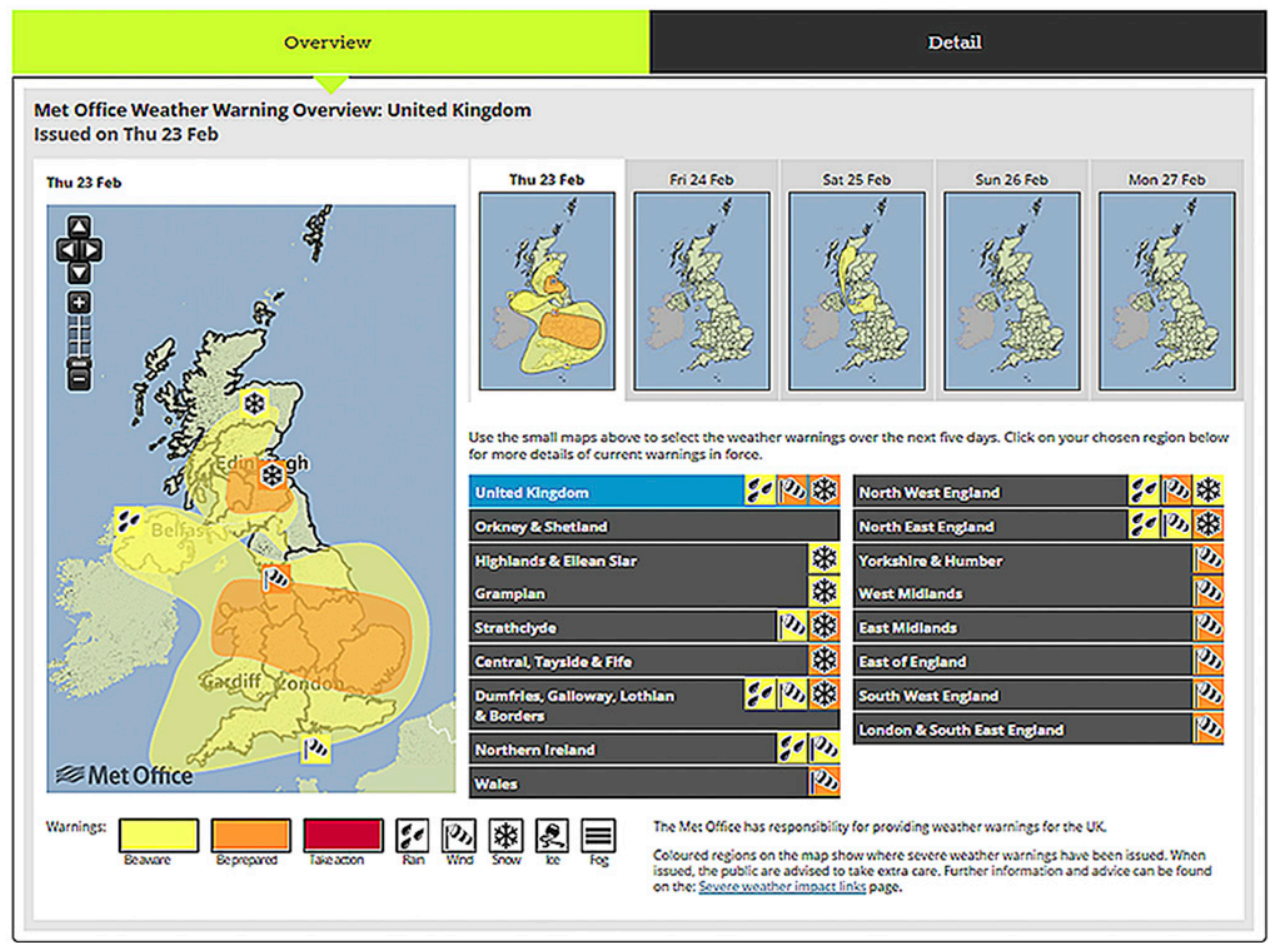

(b)
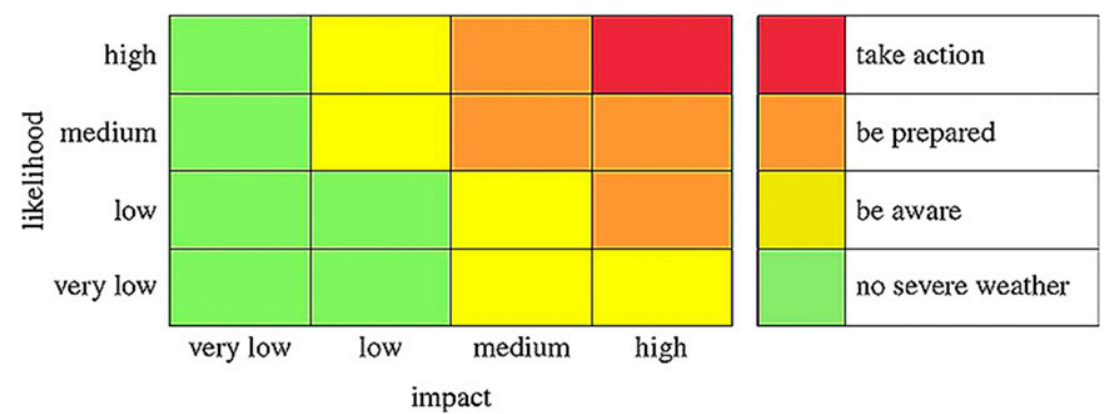

FIG. 1. (a) National severe weather warnings for the United Kingdom from the Met Office website Thursday $23 \mathrm{Feb}$; and (b) weather warning matrix format at the time the Storm Doris warnings were issued.

warnings has linked dark red with greater perceived threat and intention to act (Ash et al. 2014), while "four color" (green, yellow, amber, red) scales are linked to faster processing of warning information (Miran et al. 2017). However, misunderstanding may arise when color-coded warning schemes are not intuitively understood. In Hong Kong, where red has different cultural connotations, people have been found to be unsure of whether amber or red storm warnings represent the greater level of severity (Wong and Yan 2002). In the United Kingdom, the "green, yellow, amber, red" scheme that forms the basis of the Met Office warnings is ubiquitous (e.g., traffic lights, food labeling). The only published study to date on decision-making using the Met Office matrix suggests that the ordinal nature of the scale is well understood (Mu et al. 2018). However, this study was conducted with a highly educated student sample. Recent qualitative work on U.K. heat-wave health communication, which also uses traffic light coding but not an impact matrix, demonstrates that amber heat health alerts may not always be understood to denote greater risk than yellow alerts (Tang and Rundblad 2015).

The Met Office website provides a weather warnings guide with the objective of clarifying what each warning level means (Met Office 2018). However, this is not available in all channels that disseminate warnings, although recent articles in the national (BBC 2017a) and local (Trim and Ashe 2018) media have discussed what different levels mean. This raises the question of how 
perceptions of yellow and amber warnings issued by the Met Office differ among the wider public and whether this affects response to them.

\section{3) WARNING MAPS}

A warning map is presented to users of the Met Office's public-facing web page (Fig. 1). For warning maps aimed at the public, evidence regarding comprehension is mixed. Casteel and Downing (2013) found no added benefit of adding a map to text-only tornado warnings. However, a recent study of wildfire warnings found maps to be superior to text-only messages (Cao et al. 2016). This may reflect differences in both the nature of the events and the protective actions that should be undertaken in response to them (i.e., shelter vs evacuate)

On the Met Office website, the warning map is accompanied by a table summarizing warnings for each governmental region of the United Kingdom. Regional warnings represent the highest warning level that exists within the region. The warning for one's region may thus be higher than for one's specific local area (i.e., on the map). People using the Met Office app or searching the website for their specific location will see the warning level for their local area by default. During Storm Doris there were regionalscale amber wind warnings for each governmental region in England and Wales, with the exception of North East England. However, the map shows that large areas of South West England, South East England, East of England, North West England, Wales, and Yorkshire and Humber were within the yellow warning area. There were thus differences between regional-scale and local warnings across some of the areas affected by warnings. This raises two questions. First, are judgments of individual risk guided by regional warnings or the map? Second, when a location is close to the border of two warning levels on the map how is local risk level interpreted? Research on tornado warning maps suggests that people perceive areas near the warning periphery as lower risk than central areas, despite this not being the case (Jon et al. 2018, 2019; Lindell et al. 2016). For U.K. weather warnings, it is thus useful to determine whether those close to the border of different warning levels (e.g., yellow and amber) perceive personal risk differently than those clearly within one warning level and whether this affects behavioral response.

\section{b. Perceived risk}

In the broader risk-communication literature, links between perceived risk and behavioral response have been found in some studies but not others (see
Wachinger et al. 2013, for review). It is thus important to examine the extent to which perceptions of risk evoked by weather warnings correspond with behavioral responses. Scientific conceptualizations of risk are often characterized as a function of impact severity and probability (e.g., Spiegelhalter and and Riesch 2011). However, risk perception research suggests that likelihoods are often neglected when threats evoke strong negative feelings (e.g., Sunstein 2003). In Mu et al.'s (2018) decision experiment participants were found to link U.K. weather warning levels more strongly with impact severity than impact likelihood, unless presented with an impact matrix. At longer time scales, public willingness to prioritize future climate change impacts for adaptation is predicted by concern about the consequences of these impacts, rather than their anticipated likelihood of occurring (Taylor et al. 2017). Similarly, hazards that elicit strong negative emotions are perceived as more threatening and likely to occur than those that elicit less negative emotions (Finucane et al. 2000). However, until now, there has been little examination of the extent to which expectations of event likelihood, severity and concern elicited by U.K. weather warnings are associated with warning level and individual differences, or whether they are linked to behavioral response.

\section{c. Individual differences}

\section{1) TRUST}

Trust has been identified as a predictor of both risk perception and behavior (Siegrist and Cvetkovich 2000; Wachinger et al. 2013). In the United Kingdom, trust in authorities is associated with greater adherence to summer heat protection messages (Lefevre et al. 2015), while qualitative work examining the Environment Agency's flood warnings suggests that diminished trust in flood risk information providers may be a barrier to protective behavior (Parker et al. 2011). Outside of the United Kingdom, several studies have linked trust in forecast providers to appropriate protective behaviors across different weather risks (e.g., Kox et al. 2015; LeClerc and Joslyn 2015; Morss et al. 2016; ShermanMorris 2005). Recent evidence also suggests that, in addition to trust in forecasts leading to greater perceived threat from severe weather, warnings for more severe conditions may elicit greater trust (Losee and Joslyn 2018). When examining the role of trust in weather warning response it is thus important to identify the factors associated with perceived trustworthiness of forecast information, as well as the extent to which trust in forecast information and forecast information providers predicts behavioral response. 


\section{2) EXPERIENCE}

Direct experience of natural hazards has been linked to greater perceived risk (Wachinger et al. 2013), and willingness to take protective action (Lindell and Perry 2012). In the context of severe weather, however, findings have been mixed (Weinstein 1989). Some studies have linked severe weather experience and greater protective response (e.g., Comstock and Mallonee 2005; Schumann et al. 2018; Silver and Andrey 2014), while others have found no relationship or a negative association (e.g., Kox and Thieken 2017; Nagele and Trainor 2012; Paul et al. 2015; Potter et al. 2018). Possible reasons for this inconsistency include hazards being experienced without serious harm (Dillon et al. 2011), the salience of past events diminishing over time (Wachinger et al. 2013), media coverage leading to those who were not directly affected by the event to gain indirect experience (Silver and Andrey 2014), and differences in the way that experience is measured (e.g., recalled experience vs recorded events; Huang et al. 2016). In the United Kingdom, flood experience has been linked to greater flood risk preparedness (Harries 2012). However, it may also lead to fatalistic avoidance, inhibiting protective behaviors (Harries 2008). In the context of Storm Doris, we thus assess whether individual differences in previous (recalled) negative experience of strong winds will be associated with a stronger likelihood of changing behavior in response to wind warnings.

\section{3) WeAther ATTITUdE AND ENGAGEMENT}

Perceived vulnerability to environmental hazards has been linked to engagement with protective behaviors (Lindell and Perry 2012; Wachinger et al. 2013), though this may depend on perceived selfefficacy (Harries 2008; Wachinger et al. 2013). However, there has to date been no published research examining the extent to which perceived vulnerability to severe weather affects responses to the severe weather warnings issued by the Met Office. Likewise, the relationship between individuals' engagement with the subject of weather and response to weather warnings has not been examined in the United Kingdom. Internationally, a small number of U.S. studies have, however, linked greater weather engagement with more appropriate weather warning understanding and response (Stewart 2009; Stewart et al. 2012). In a U.K. context it is thus important to examine whether individual attitudes toward the subject of weather, including perceived vulnerability and engagement, are predictive of behavioral response to weather warnings.

\section{4) DEMOGRAPHIC CHARACTERISTICS}

The relationship between demographic characteristics and weather warning response has been widely studied. However, findings have been inconsistent. Some studies have linked home ownership to protective action (Kox and Thieken 2017; Sherman-Morris 2013), while others have not (Morss et al. 2016). Likewise, women have reported greater protective intentions in some studies (Kim et al. 2014; Potter et al. 2018; Silver and Andrey 2014), but not others (Silver and Andrey 2014). As Sherman-Morris (2013) notes, this is likely due to these relationships being context dependent, with the nature of specific hazards determining the link between demographic characteristics and responses. We thus control for their role in specific weather risk contexts.

\section{Research questions}

This study explores both the U.K. public's interpretation of wind warnings issued during Storm Doris and the factors associated with perceived risk elicited by the warning, trust in the warning, recalled response to the warning, and anticipated future response to similar warnings. Of particular interest was the extent to which the warning level for a local area at the time of Storm Doris predicted individual responses when individual differences were controlled for. Consequently, we addressed the following five research questions (RQ):

RQ1 To what extent do individuals understand that wind warnings issued by the Met office are impact-based?

RQ2 To what extent are individuals' interpretations of local wind warning levels consistent with the Storm Doris warning map shown on the Met Office website?

RQ3 To what extent do warning characteristics and individual differences predict anticipated local risk (likelihood, severity, concerningness) in response to wind warnings?

RQ4 To what extent do wind warning characteristics and individual differences predict trust in the forecast?

RQ5 To what extent do warning characteristics and individual differences predict recalled and anticipated response to wind warnings?

\section{Methodology}

\section{a. Participants}

A total of 600 participants from England and Wales were recruited from panels maintained by the research 
company ResearchNow to take part in an online survey. Participants completing the survey were awarded points by ResearchNow, which could be exchanged for gift cards. A total of 48 participants were excluded from the analysis because their postcode region did not clearly fall within an area covered by wind warnings on the Met Office's warning maps for 21-23 February 2017 (the Storm Doris period). The remaining 552 (55\% female, $n=306$ ) ranged in age from 18 to 85 $[$ mean $=44$, standard deviation $(\mathrm{sd})=16$, with a median estimated household income of $£ 30,000-£ 39,999$. Of these, $42 \%$ had completed at least a bachelor's degree and $62 \%$ were home owners. Ethical approval for this study was granted by the Leeds University Business, Environment and Social Sciences joint Faculty Research Ethics Committee (AREA FREC).

\section{b. Weather context and local warnings}

Storm Doris was first named on 21 February 2017 when warnings for wind, snow, and rain were first issued by the Met Office for 23 February. On the night between the 22 and 23 February the storm underwent explosive cyclogenesis, and was labeled a "weather bomb" (Met Office 2017a). It led to strong winds across England and Wales with gusts of up to $94 \mathrm{mph}$, causing power cuts and major disruption to transport (BBC 2017b; Met Office 2017a). It was reported in the national media to have led to at least one fatality and an estimated $£ 400$ million in economic losses (BBC 2017b; White 2017). Storm Doris was the fourth named storm to occur during the 2016/17 winter storm season. While preceding storms Angus, Barbara, and Connor did bring localized strong winds to some areas of the United Kingdom, Doris led to widespread disruption across the country (Met Office 2017b). The survey took place between 10 and 14 April 2017, within seven weeks of the Storm Doris warnings. Figure 1 displays Met Office warnings for Thursday 23 February when wind warnings covered the widest geographic area. Yellow or amber wind warnings were in place over most of England and Wales, while snow warnings were issued for Scotland and North East England. Warnings for rain were also issued for Northern Ireland and North West England. Between Storm Doris and the survey, no other named storms or severe weather warnings were issued. In the present analysis, the map (rather than regional-scale warnings) is used as a guide to participants' local wind warning level, although all participants come from areas where regional-scale amber warnings were in place. This was done first, to enable a comparison between warning levels, and also because the map reflects the warnings delivered by the Met Office app.
Based upon their postcode sector, participants were classified as being in an amber or yellow area if their postcode location fell clearly into one or the other on the map. Participants were classified as "border" when their postcode location fell into both amber and yellow warning areas. Each category was coded as a dummy variable. Amber warning was the reference category in all analyses. Information on warnings for specific postcode areas was not, at the time of data collection, retained by the Met Office. Hence, coding was done by superimposing postcode maps on Met Office warning maps for 23 February 2017 and manually identifying which category each postcode area fell into.

\section{c. Measures}

\section{1) UNDERSTANDING OF IMPACT-BASED FORECASTS}

The extent to which participants interpreted forecasts as being impact based (vs phenomena based) was examined by level of agreement $(1=$ strongly disagree, $5=$ strongly agree) with six statements (Table 1), presented in randomized order. Three statements were consistent with an appropriate impact-based interpretation of warnings (e.g., "Warnings for strong winds are based on what the impacts of strong wind could be for a particular area"). Three were consistent with an inappropriate phenomenabased interpretation of warnings (e.g., "The conditions needed to trigger a severe weather warning are the same across the whole UK").

\section{2) INTERPRETATION OF LOCAL WARNING LEVEL}

Participants were shown the Storm Doris warnings for 23 February onscreen (Fig. 1) and asked to indicate which wind warnings they perceived to be in place for their local area. Participants could select "yellow," amber," or "not sure." A small number of participants $(2 \%, n=11)$ selected more than one option. Responses were coded as amber if both "amber" and "yellow" were selected, reflecting the higher warning level.

\section{3) ANTICIPATED RISK}

Participants were instructed to imagine that they saw the weather warnings from 23 February 2017 (picture onscreen) again, and use sliders to rate how likely $(0=$ impossible: $100=$ certain $)$, severe $(0=$ not severe at all: $100=$ very severe $)$ and concerning $(0=$ not concerning at all: $100=$ very concerning) they would expect the impacts of strong wind to be in their local area.

\section{4) TRust IN THE FORECAST}

Trust in the Storm Doris forecast was rated on a slider scale of 0 (= would not trust at all) to 100 (= would trust completely). 
TABLE 1. Summary of items comprising multiple-item questions.

\begin{tabular}{lc}
\hline \hline Scale items & Response options \\
\hline
\end{tabular}

Interpretation of impact-based forecasts

The conditions needed to trigger a severe weather warning are the same across the whole United Kingdom ${ }^{\mathrm{a}}$

The conditions needed to trigger a severe weather warning are different for different parts of the United Kingdom ${ }^{\mathrm{b}}$

A red warning for strong winds will be more serious for areas of the United Kingdom that are less used to strong winds ${ }^{a}$

It takes more severe strong winds to trigger a red warning for strong winds in areas that experience a lot of strong winds ${ }^{\mathrm{b}}$

Warnings for strong winds are based only on the maximum wind speed that is expected to occur ${ }^{\mathrm{a}}$

Warnings for strong winds are based on what the impacts of strong winds could be for a particular area $^{\mathrm{b}}$

Understandability

This weather warning is easy to understand

There are some parts of this weather warning that I find confusing ${ }^{\mathrm{c}}$

I like the design of this weather warning

I think that the design of this weather warning could be improved ${ }^{\mathrm{c}}$

$$
\begin{aligned}
& 1=\text { strongly disagree } \\
& 2=\text { disagree } \\
& 3=\text { neither agree nor disagree } \\
& 4=\text { agree } \\
& 5=\text { strongly agree }
\end{aligned}
$$

Trust in the Met Office

The U.K. weather warning shown in this questionnaire is provided by the Met Office. How do you feel about the Met Office? (Choose the point on each of the scales below that you think best represents your views.)

Has different values: Shares my values

Different goals to me: Same goals to me

Opposes my views: Supports my views

Does not act like me: Acts like me

Incompetent: Competent

Inaccurate: Accurate

Unreliable: Reliable

Harmful: Beneficial

Low ability: High ability

Irresponsible: Responsible

Unfriendly: Friendly

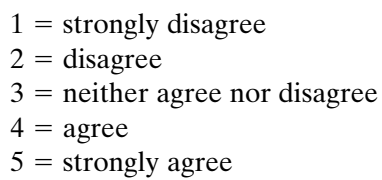

Weather Attitude

Interest subscale

I pay a lot of attention to weather forecasts

I am interested in weather forecasts

Vulnerability subscale

The weather has a big impact on my day-to-day life

Bad weather makes it difficult for me to get around

$1=$ very untrue for me

$2=$ mostly untrue for me

$3=$ sometimes true for me

I worry about the weather a lot

$4=$ mostly true for me

Disengagement subscale

Weather forecasts are not relevant to me

$5=$ very true for me

I hardly ever think about the weather

The weather does not affect my daily activities very much

\footnotetext{
${ }^{a}$ Phenomena-based statement (incorrect).

${ }^{\mathrm{b}}$ Impact-based statement (correct).

${ }^{\mathrm{c}}$ Reverse coded.
}

\section{5) RECALLED RESPONSE}

Participants were shown a prompt comprising a screenshot of national weather warnings issued on 23 February 2017 from the Met Office's website (see Fig. 1), and asked whether they remembered seeing or receiving a warning for wind during this time.
The 315 who answered "yes" were asked to indicate whether it "had any effect on your decision-making or behavior after seeing it?" by choosing all behavioral responses, from a list of 20 , that they recalled (see online supplemental material for a full breakdown). These items, which were adapted from responses to previous Met Office surveys, included making decisions 
to avoid the potential negative impacts of bad weather (e.g., "I shopped early") and deliberate protective actions (e.g., "I secured things around my property"). Response were coded as a binary variable $1=$ protective behavioral response, $0=$ no protective response taken. It should be noted that not all protective responses reported represent optimal protective behavior (e.g., "walking everywhere" to avoid transport disruption may increase individual risk from strong wind).

\section{6) Anticipated RESPONSE}

Anticipated response to seeing the warning again was measured by the question "do you think that seeing this forecast would affect your decisionmaking or behavior?" (coded as $0=$ no/do not know, $1=$ yes).

\section{7) UNDERSTANDABILITY}

Perceived understandability of the weather warning displayed was measured using mean level of agreement $(1=$ strongly disagree, $5=$ strongly agree $)$ with four items (e.g., "This weather warning is easy to understand"). Principal components analysis indicated that these items loaded onto a single scale (Cronbach's alpha $=0.76$; negatively phrased items were reverse coded). Scale items are detailed in Table 1.

\section{8) Trust in the Met Office}

Trust in the Met Office was measured using 11 items adapted from Earle and Cvetkovich (1995) (see Table 1). Participants were presented with bipolar dimensions (e.g., "not trustworthy-trustworthy," "unreliable-reliable") and selected the point, on a five-point scale, that best reflected their opinion of the Met Office. Principal components analysis indicated that all items loaded onto a single scale $($ Cronbach's alpha $=0.94)$.

\section{9) Negative EXPERIENCE OF STRONG WIND}

Participants were asked whether they had ever personally experienced any negative consequences as a result of strong wind (recoded as no/do not know $=0$, yes $=1$ ).

\section{0) Attitude to weather}

Attitude toward weather was measured using agreement with eight statements (Table 1) on a scale of $1=$ very untrue for me, $5=$ very true for me). These items were not directly adapted from existing scales, but were based on considerations of the wider riskcommunication literature (e.g., Wachinger et al. 2013), and qualitative responses given by participants in earlier Met Office postevent surveys. Principal components analysis indicates that the items loaded onto three subscales: interest in weather (e.g., "I am interested in weather forecasts"), perceived vulnerability (e.g. "Bad weather makes it difficult for me to get around"), and disengagement (e.g. "I hardly ever think about the weather"). Cronbach's alpha $>0.70$ for all subscales.

\section{1) DEMOGRAPHIC CHARACTERISTICS}

We recorded participants' age, sex $(0=$ male, $1=$ female), education (recoded as $0=$ no higher education, $1=$ higher education $)$, household income band $(1=$ less than $£ 10,000,2=£ 10,000-£ 19,999, \ldots, 15=£ 150,000$ or more), and home ownership $(0=$ not a home owner, $1=$ home owner)

\section{Results}

a. To what extent do U.K. residents understand that the severe wind warnings issued by the Met Office are impact based?

Figure 2 shows agreement with statements about the impact-based (vs phenomena-based) nature of U.K. weather warnings. For all statements, a substantial proportion of participants selected "neither agree nor disagree," indicating that many felt that they did not know the answer. Most participants (58\%) appropriately agreed that "Warnings for strong wind are based on what the impacts of strong wind could be for a particular area," indicating broad awareness that warnings are based on potential impacts. However, the fact that the conditions needed to trigger weather warnings are different for different regions was not well understood, with only $37 \%$ agreeing that "it takes more severe strong wind to trigger a red warning for strong wind in areas that experience a lot of strong wind."

\section{b. Are U.K. residents' interpretations of their local risk level during Storm Doris consistent with the map shown on the Met Office website?}

In total 491 participants responded to the question asking them to indicate which warnings were in place for their area according to the 23 February 2017 forecast. According to the warning map, 201 of the participants who responded to this question were in amber warning areas, 100 were on the border between yellow and amber areas, and 190 were in yellow warning areas. Regional-level amber warnings were, however, in place for all regions sampled. 
Warnings for strong winds are based on what the impacts of strong winds could be for a particular area (impact based; $n=538$ )

Warnings for strong winds are based only on the maximum windspeed that is expected to occur (phenomena based; $n=540$ )

A red warning for strong winds will be more serious for areas of the UK that are less used to strong winds (phenomena based; $n=541$ )

The conditions needed to trigger a severe weather warning are different for different parts of the UK (impact based; $n=541$ )

It takes more severe strong winds to trigger a red warning for strong winds in areas that experience a lot of strong wind (impact based; $n=542$ )

The conditions needed to trigger a severe weather warning are the same across the whole UK (phenomena based; $n=541$ )

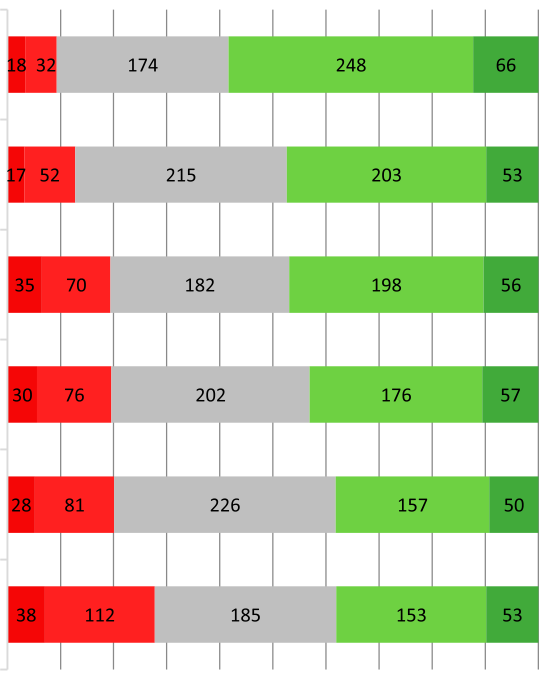

$\begin{array}{llllllllllllllll}0 & 0 & 10 \% & 20 \% & 30 \% & 40 \% & 50 \% & 60 \% & 70 \% & 80 \% & 90 \% & 100 \%\end{array}$

$\square$ Strongly disagree $\quad$ Disagree $\quad$ Neither agree nor disagree $\quad$ Agree $\quad$ Strongly agree

FIG. 2. Percentage of participants agreeing with statements about the impactbased (vs phenomena based) nature of severe weather warnings in the United Kingdom. Frequencies are given within the bars for each response type for each question.

For amber warning areas on the map, $80 \%(n=160)$ of participants correctly interpreted their local warning level as amber, while $7 \%(n=14)$ incorrectly interpreted it to be yellow and $13 \%(n=27)$ were "not sure." In border areas, $60 \%(n=60)$ participants interpreted their local warning level as amber, $26 \%$ $(n=26)$ yellow, $14 \%(n=14)$ were "not sure." In yellow areas $52 \%(n=98)$ interpreted their local warning as yellow and $32 \%(n=62)$ as amber, while $16 \%(n=30)$ were "not sure." We therefore find that very few participants in amber warning areas underestimated their local warning level. Likewise, those in border areas tended to interpret their warning level as amber. For those in yellow warning areas on the map, a substantial minority identified their local warning level as amber. The selection of the amber warning by these participants was not wholly incorrect as amber-level regional warnings were in place. However, it was inconsistent with the map.

c. To what extent do warning characteristics and individual differences predict anticipated local risk and trust in forecast?

Table 2 displays mean scores on each continuous dependent and independent variable by warning level. Ratings of anticipated likelihood, impact severity, concern, and trust in the forecast were highest for participants in amber warning regions and lowest for those in yellow warning regions, with border regions falling between the two. As the four dependent variables were highly correlated with one another $(r \geq 0.50, p \leq 0.001$ for all $)$, a multivariate analysis of covariance (MANCOVA) was used to assess the factors predicting them. Warning level was entered as a fixed factor, while individual difference measures were entered as covariates. Table 3 reports unstandardized regression coefficients for each predictor on each dependent variable. Full details of the MANCOVA and associated $p$ values can be found in the supplemental material. Here, we focus on those predictors that reach statistical significance at $p \leq 0.05$ in the MANCOVA.

Among those in yellow warning areas anticipated likelihood, severity, concern and trust in the forecast were lower than those in amber warning areas. Anticipated likelihood was lower for those in border areas than amber areas. Trust in the Met Office was associated with greater anticipated likelihood, concern and trust in the forecast. Greater perceived vulnerability predicted greater anticipated likelihood, impact severity, and concern. Home ownership was associated with greater anticipated severity of impacts. Perceived understandability was associated with greater trust in the forecast. While $175(32 \%)$ of all participants reported negative experience of strong winds, this did not independently contribute the prediction of our 
TABLE 2. Mean (standard deviation) scores for all continuous dependent and independent variables by warning area.

\begin{tabular}{|c|c|c|c|c|c|c|c|c|}
\hline & \multicolumn{2}{|c|}{ Yellow } & \multicolumn{2}{|c|}{ Border } & \multicolumn{2}{|c|}{ Amber } & \multicolumn{2}{|c|}{ Overall } \\
\hline & Mean & (sd) & Mean & (sd) & Mean & (sd) & Mean & (sd) \\
\hline \multicolumn{9}{|l|}{ Dependent variables } \\
\hline Anticipated likelihood & 56.92 & $(20.35)$ & 61.64 & $(18.84)$ & 67.50 & $(17.43)$ & 62.24 & $(19.42)$ \\
\hline Anticipated severity & 50.78 & $(20.54)$ & 57.38 & (19.21) & 60.87 & $(18.15)$ & 54.25 & $(19.80)$ \\
\hline Anticipated concern & 45.71 & $(23.95)$ & 51.51 & $(22.69)$ & 56.60 & $(21.51)$ & 51.40 & $(23.17)$ \\
\hline Trust in the forecast & 62.03 & $(21.90)$ & 64.94 & (18.79) & 68.25 & $(19.84)$ & 65.18 & $(20.58)$ \\
\hline \multicolumn{9}{|l|}{ Independent variables } \\
\hline Trust in the Met Office & 3.79 & $(0.73)$ & 3.72 & $(0.70)$ & 3.78 & $(0.75)$ & 3.77 & $(0.73)$ \\
\hline Weather attitude: Vulnerability & 2.84 & $(0.85)$ & 2.69 & $(0.83)$ & 2.77 & $(0.85)$ & 2.78 & $(0.85)$ \\
\hline Weather attitude: Interest & 3.49 & $(0.97)$ & 3.46 & $(0.93)$ & 3.48 & $(0.92)$ & 3.48 & $(0.94)$ \\
\hline Weather attitude: Disengagement & 2.44 & $(0.85)$ & 2.50 & $(0.77)$ & 2.68 & $(0.89)$ & 2.55 & $(0.85)$ \\
\hline Perceived understandability & 3.23 & $(0.83)$ & 3.19 & $(0.84)$ & 3.34 & $(0.67)$ & 3.27 & $(0.78)$ \\
\hline
\end{tabular}

measures of anticipated risk or trust in forecast when other independent variables were controlled for.

\section{d. To what extent do warning characteristics and individual differences predict recalled and anticipated response to wind warnings?}

\section{1) RECALLED RESPONSE}

Binary logistic regression was used to examine the predictors of recalled response to the Storm Doris warnings $(1=$ protective response $)$. Model 1 contained local warning level (amber as the reference class), negative experience of strong winds, perceived understandability, trust in the Met Office, weather attitude (interest, vulnerability, disengagement subscales), and demographic characteristics (age, sex, education, income, and home ownership). Model 2 added anticipated risk (likelihood severity and concern) and trust in the forecast. Full statistical output from this analysis can be found in the supplemental material.

In model 1 protective response was associated with greater negative experience of strong winds, interest in weather and perceived vulnerability (Table 4). In model 2, protective response was associated with greater negative experience, interest in weather and anticipated concern. In model 2, perceived vulnerability ceased to make an independent contribution to the model. This suggests that the association between perceived vulnerability and anticipated response is accounted for by the relationship between perceived vulnerability and anticipated concern.

\section{2) ANTICIPATED RESPONSE TO FUTURE WARNINGS}

Binary logistic regression assessed the predictors of anticipated response to seeing the warning again (Table 5). Two models were tested. Model 1 contained

TABLE 3. Linear regression models, predicting anticipated likelihood, anticipated severity, concern, and trust into the forecast $(n=509)$. Note * is significant at $p \leq 0.05, * *$ at $p \leq 0.0$, and *** at $p \leq 0.001 ; B$ (SE) denotes unstandardized regression coefficient.

\begin{tabular}{|c|c|c|c|c|}
\hline & Anticipated likelihood & Anticipated severity & Anticipated concern & Forecast trustworthiness \\
\hline & $B(\mathrm{SE})$ & $B(\mathrm{SE})$ & $B(\mathrm{SE})$ & $B(\mathrm{SE})$ \\
\hline Warning: Yellow & $-10.67(1.89)^{* * *}$ & $-9.25(1.90) * * *$ & $-10.10(2.12)^{* * *}$ & $-5.31(1.85)^{* *}$ \\
\hline Warning: Border & $-5.93(2.24)^{* *}$ & $-5.50(2.24)$ & $-2.50(2.51)$ & $-2.08(2.19)$ \\
\hline Age & $0.02(0.06)$ & $-0.01(0.06)$ & $0.14(0.07)$ & $-0.02(0.06)$ \\
\hline Sex $(1=$ female $)$ & $0.09(1.71)$ & $0.57(1.72)$ & $1.87(1.92)$ & $0.97(1.67)$ \\
\hline Education ( 1 = higher education) & $-0.38(1.75)$ & $-2.05(1.75)$ & $-1.83(1.96)$ & $0.57(1.71)$ \\
\hline Income & $0.17(0.31)$ & $-0.06(0.31)$ & $-0.21(0.35)$ & $0.35(0.30)$ \\
\hline Homeowner (1 = homeowner) & $2.47(1.94)$ & $5.52(1.94)^{* *}$ & $1.24(2.18)$ & $1.52(1.90)$ \\
\hline Negative experience $(1=$ yes $)$ & $0.88(1.81)$ & $0.63(1.81)$ & $3.18(2.03)$ & $1.89(1.77)$ \\
\hline Understandability & $0.16(1.14)$ & $0.77(1.14)$ & $0.62(1.28)$ & $3.44(1.11)^{* *}$ \\
\hline Trust in Met Office & $4.65(1.36)^{* * *}$ & $2.67(1.36)$ & $3.88(1.52)^{* *}$ & $10.59(1.33)^{* * *}$ \\
\hline Weather attitude: Interest & $1.70(1.20)$ & $0.96(1.20)$ & $-0.71(1.34)$ & $1.40(1.17)$ \\
\hline Weather attitude: Vulnerability & $2.27(1.17)^{*}$ & $4.22(1.17)^{* * *}$ & $10.41(1.31)^{* * *}$ & $1.24(1.14)$ \\
\hline Weather attitude: Disengagement & $-0.27(1.04)$ & $1.06(1.04)$ & $0.36(1.17)$ & $0.33(1.02)$ \\
\hline$R^{2}$ & 0.13 & 0.12 & 0.21 & 0.24 \\
\hline
\end{tabular}


TABLE 4. Hierarchical binary logistic regression examining predictors of protective response to the Storm Doris warnings $(n=297)$. Note * is significant at $p \leq 0.05, * *$ at $p \leq 0.0$, and ***at $p \leq 0.001 ; B$ (SE) denotes unstandardized regression coefficient, and $\operatorname{Exp}(\beta)$ denotes standardized regression coefficient.

\begin{tabular}{|c|c|c|c|c|}
\hline & \multicolumn{2}{|c|}{ Model 1} & \multicolumn{2}{|c|}{ Model 2} \\
\hline & $B(\mathrm{SE})$ & $\operatorname{Exp}(\beta)$ & $B(\mathrm{SE})$ & $\operatorname{Exp}(\beta)$ \\
\hline Warning: Yellow & $-0.25(0.30)$ & 0.78 & $0.04(0.33)$ & 1.04 \\
\hline Warning: Border & $0.27(0.38)$ & 1.31 & $0.40(0.39)$ & 1.49 \\
\hline Age & $<0.01(0.01)$ & 1.00 & $-0.01(0.01)$ & 0.99 \\
\hline $\operatorname{Sex}(1=$ female $)$ & $-0.15(0.27)$ & 0.86 & $-0.22(0.28)$ & 0.80 \\
\hline Education $(1=$ higher education $)$ & $0.03(0.28)$ & 1.03 & $-0.01(0.29)$ & 0.99 \\
\hline Income & $-0.04(0.05)$ & 0.96 & $-0.06(0.05)$ & 0.94 \\
\hline Home owner (1 = homeowner $)$ & $-0.54(0.33)$ & 0.58 & $-0.54(0.34)$ & 0.58 \\
\hline Understandability & $-0.23(0.19)$ & 0.80 & $-0.30(0.20)$ & 0.74 \\
\hline Negative experience $(1=$ yes $)$ & $0.69(0.29)$ & $2.00 *$ & $0.63(0.30)$ & $1.87 *$ \\
\hline Trust in Met Office & $0.31(0.23)$ & 1.36 & $0.08(0.25)$ & 1.08 \\
\hline Weather attitude: Interest & $0.41(0.20)$ & $1.50 *$ & $0.44(0.21)$ & $1.56^{*}$ \\
\hline Weather attitude: Vulnerability & $0.52(0.19)$ & $1.68 * *$ & $0.38(0.21)$ & 1.46 \\
\hline Weather attitude: Disengagement & $0.01(0.19)$ & 1.01 & $0.02(0.19)$ & 1.02 \\
\hline Anticipated likelihood & & & $0.01(0.01)$ & 1.01 \\
\hline Anticipated severity & & & $-0.02(0.01)$ & 0.98 \\
\hline Concern & & & $0.02(0.01)$ & $1.02 *$ \\
\hline Trust in forecast & & & $0.01(0.01)$ & 1.01 \\
\hline & \multirow{2}{*}{\multicolumn{2}{|c|}{$\begin{array}{l}46.41 * * * \\
0.20\end{array}$}} & \multirow{2}{*}{\multicolumn{2}{|c|}{$\begin{array}{l}59.53^{* * *} * \\
0.25\end{array}$}} \\
\hline Nagelkerke $R^{2}$ & & & & \\
\hline
\end{tabular}

warning level, demographic characteristics (age, sex, education, income, home ownership), trust in the Met Office, perceived understandability, negative experience of strong wind, and weather attitude (interest, vulnerability, disengagement subscales). Model 2, added anticipated risk (likelihood, severity, concern) and trust in the forecast. Full statistical output from this analysis can be found in the supplemental material.

No association was found between warning level and anticipated response. In model 1, perceived vulnerability, trust in the Met Office, and negative experience were positively associated with anticipated response. In model 2 , concern emerged as the strongest predictor of anticipated response, with anticipated severity making a smaller contribution to the model. Trust in the Met Office and negative experience continued to contribute significantly. The independent contribution of perceived vulnerability ceased to be significant, again suggesting that the association between perceived vulnerability and anticipated response is accounted for by the relationship between perceived vulnerability and anticipated concern.

\section{Discussion}

This study explored how members of the U.K. public interpret and respond to the Met Office's impactbased weather warnings. Through a postevent survey conducted following the Storm Doris wind warnings, we examined understanding of the impact-based nature of U.K. weather warnings (RQ1) and the consistency of local warning level interpretations with actual local weather warning levels (RQ2), along with the predictors of anticipated local risk (RQ3), predictors of forecast trustworthiness (RQ4), and predictors of recalled and anticipated response (RQ5).

a. To what extent do U.K. residents understand that the severe wind warnings issued by the Met Office are impact based?

Over half of our participants correctly related warning levels to the potential impacts of severe weather. This is in keeping with U.S. research suggesting that people tend to interpret warnings as being based on the consequences of severe weather by default (Williams et al. 2017). However, there was lower recognition of the fact that the meteorological conditions under which warnings are issued differ between regions, along with a generally high level of uncertainty about each of the statements. Failure to realize that warning thresholds differ between locations could lead people in areas that experience more frequent and intense meteorological phenomena (e.g., wind, precipitation, snow) to underestimate local risk implied by warnings on the grounds that they are used to these events occurring and thus more resilient than those in other areas. This highlights a need for clearer communication with the U.K. public about the fact that warning thresholds are 
TABLE 5. Hierarchical binary logistic regression examining predictors of anticipated response to future warnings $(n=509)$. Note $*$ is significant at $p \leq 0.05, * *$ at $p \leq 0.0$, and $* * *$ at $p \leq 0.001 ; B$ (SE) denotes unstandardized regression coefficient, and $\operatorname{Exp}(\beta) \operatorname{denotes}$ standardized regression coefficient.

\begin{tabular}{|c|c|c|c|c|}
\hline & \multicolumn{2}{|c|}{ Model 1} & \multicolumn{2}{|c|}{ Model 2} \\
\hline & $B(\mathrm{SE})$ & $\operatorname{Exp}(\beta)$ & $B(\mathrm{SE})$ & $\operatorname{Exp}(\beta)$ \\
\hline Warning: Yellow & $-0.14(0.23)$ & 0.87 & $0.39(0.26)$ & 1.47 \\
\hline Warning: Border & $0.17(0.27)$ & 1.18 & $0.40(0.30)$ & 1.49 \\
\hline Age & $<0.01(0.01)$ & 1.00 & $-0.01(0.01)$ & 0.99 \\
\hline $\operatorname{Sex}(1=$ female $)$ & $-0.06(0.21)$ & 0.95 & $-0.13(0.23)$ & 0.88 \\
\hline Education $(1=$ higher education $)$ & $0.23(0.22)$ & 1.25 & $0.36(0.24)$ & 1.44 \\
\hline Income & $-0.07(0.04)$ & 0.93 & $-0.08(0.04)$ & 0.92 \\
\hline Home owner ( 1 = homeowner $)$ & $0.35(0.24)$ & 1.41 & $0.2(0.26)$ & 1.22 \\
\hline Negative experience $(1=$ yes $)$ & $0.69(0.22)$ & $2.00 * *$ & $0.68(0.24)$ & $1.97 * *$ \\
\hline Understandability & $0.07(0.14)$ & 1.08 & $0.02(0.16)$ & 1.02 \\
\hline Trust in Met Office & $0.67(0.17)$ & $1.95 * * *$ & $0.60(0.2) 0$ & $1.81^{* *}$ \\
\hline Weather attitude: Interest & $0.26(0.15)$ & 1.30 & $0.32(0.16)$ & 1.37 \\
\hline Weather attitude: Vulnerability & $0.54(0.15)$ & $1.71 * * *$ & $0.23(0.17)$ & 1.26 \\
\hline Weather attitude: Disengagement & $-0.06(0.14)$ & 0.94 & $-0.16(0.15)$ & 0.86 \\
\hline Anticipated likelihood & & & $<0.01(0.01)$ & 1.00 \\
\hline Anticipated severity & & & $0.02(0.01)$ & $1.02 *$ \\
\hline Concern & & & $0.03(0.01)$ & $1.03 * * *$ \\
\hline Trust in forecast & & & $<0.01(0.01)$ & 1.00 \\
\hline$\chi^{2}$ & \multirow{2}{*}{\multicolumn{2}{|c|}{$\begin{array}{r}104.25 \\
0.25\end{array}$}} & \multirow{2}{*}{\multicolumn{2}{|c|}{$\begin{array}{r}175.66 \\
0.39\end{array}$}} \\
\hline Nagelkerke $R^{2}$ & & & & \\
\hline
\end{tabular}

related to local impacts, and are different for different regions.

\section{b. Are U.K. residents' interpretations of their local risk level during Storm Doris consistent with the map shown on the Met Office website?}

When shown the Storm Doris warning map from the Met Office website (23 February 2017), very few participants underestimated the warning level for their local area. A large majority of those in amber warning areas correctly identified their warning level as amber. Indeed, those on the border between amber and yellow warning areas tended to select amber, as did a substantial minority of those in the yellow warning areas. The latter finding could be attributable to the fact that regionallevel amber warnings were in place for all participants surveyed. This may indicate that when warning levels are unclear (i.e., because they are on the border between warning levels) or ostensibly inconsistent (i.e., with warnings for one's general region being higher than one's specific location), people interpret their own warning as being the higher of the two. It may also indicate that some people struggle to correctly pinpoint their local area on a map.

Taken together, this suggests that the U.K. public tend not to underestimate warning levels for their local area, although overestimation may occur. When local warnings levels are unclear (i.e., where a location is close to the border between amber and yellow warning areas) people tend to perceive themselves as being in the higher warning level. As the boundaries of warning area do not have perfect deterministic accuracy, this could reflect an appropriate precautionary response. However, where people located far from warning area boundaries overestimate their local warning levels this may lead to "cry wolf" effects, when local conditions are repeatedly less severe than anticipated. While testing this directly is beyond the scope of the current study, it does highlight the value of making it easy for people to identify where their local area lies with respect to geographic warning areas. This has been implemented on recent versions of the Met Office's warning map, which allows website visitors to zoom in on specific locations.

\section{c. To what extent do warning characteristics and individual differences predict anticipated local risk (likelihood, severity, concerningness) in response to wind warnings?}

Strong correlations were found between anticipated likelihood, severity and concern. This is consistent with research indicating that threats evoking stronger negative emotions (e.g., concern) are perceived as being more likely to occur and have more severe negative consequences (Finucane et al. 2000). This is also consistent with fact that, all three measures were positively predicted by perceived vulnerability to severe weather. A strong correlation between all anticipated risk measures and warning trustworthiness was also in evidence, while trust in the Met Office as an institution 
was a significant predictor of anticipated likelihood and concern. This may indicate that people who perceive weather warnings (and their providers) to be trustworthy are more likely to believe that they convey a personal threat. As noted, however, recent experimental evidence suggests that this association may be bidirectional, with more severe warnings also eliciting greater trust (Losee and Joslyn 2018).

As might be expected, those in yellow warning areas anticipated strong winds to be less likely, severe, and concerning than those in amber areas. For participants in border areas, ratings of likelihood, severity, and concern fell between those for yellow and amber regions. Overall, this suggests a generally appropriate interpretation of the Met Office warning levels, but with some ambiguity in risk perception among those on the border between different warning levels. This is consistent with our finding that some participants in border areas perceived their local warning level to be yellow, while others perceive it to be amber. It may also reflect a broader tendency for those on the periphery of warning areas to perceive their own level of risk to be lower than those in the center (Jon et al. 2018; Lindell et al. 2016). Once again, this highlights the importance of members of the public being able to identify the warning level in place for their location.

Home ownership was associated with anticipated impact severity, perhaps reflecting homeowners' greater direct responsibility for repairing property damage. However, this did not correspond with greater concern. No other demographic characteristic made an independent contribution to the prediction of the anticipated risk variables.

Together these findings indicate that for U.K. wind warnings, such as those issued for Storm Doris, anticipated personal risk is driven not just by the local warning level but by individual differences in perceived vulnerability to weather and trust in warning providers. It should, however, be kept in mind that this study was intentionally conducted following a severe weather event. Hence, participants' perceptions of vulnerability-and thus anticipated risk-may have been influenced by the salience (or "availability") of their Storm Doris experiences (e.g., exacerbated by negative experience or attenuated by lack of negative experience).

\section{d. To what extent do wind warning characteristics and individual differences predict trust in the forecast?}

Trust in the forecast had a strong positive association with trust in the Met Office as an institution. It was also negatively associated with being in a yellow (vs amber) warning area and positively associated with perceived warning understandability. The fact that participants in amber warning locations trusted the forecast more than those in yellow warning locations corroborates Losee and Joslyn's (2018) findings that warnings for more severe events can elicit greater trust than those for less severe events. As trust in the forecast could not have conceivably affected the geographic areas covered by yellow and amber warnings, it is reasonable to infer that the severity of the warning level influenced trust. The positive association between perceived understandability and trust in the forecast may suggest that messages that are perceived to be difficult to understand are less likely to be trusted. While perceived understanding of weather and climate information does not always correspond with objective understanding (Lorenz et al. 2015; Wong and Yan 2002), perceived "ease of understanding" is closely tied to communication preferences (Taylor et al. 2015). Our findings therefore demonstrate the importance of ensuring that forecasts are perceived as easy to understand as well as being correctly understood.

\section{e. To what extent do warning characteristics and individual differences predict recalled and anticipated response to wind warnings?}

With respect to decisions about behavioral responses to the Storm Doris warnings, findings were similar for both recalled response and anticipated future response. In both cases, concern evoked by the warning was the largest predictor of protective response. Consistent with findings from the broader literature on natural hazards, perceived vulnerability was associated with both recalled and anticipated response (Lindell and Perry 2012; Wachinger et al. 2013). However, it ceased to provide a unique contribution to the prediction once concern was entered. This suggests that those who perceive themselves to be vulnerable to weather risks tend to be more concerned when faced with severe weather warnings, and that this is linked to greater willingness to engage in protective responses. In terms of weather attitudes, we also find that those with a greater general interest in weather were more likely to report having undertaken a protective response. This corresponds with findings from the United States linking individual "weather salience" to protective behavior (Stewart 2009; Stewart et al. 2012). However, caution should be advised in interpreting this finding. The fact that it was significantly associated with recalled but not anticipated response could also indicate that those with greater interest in weather found it easier to recall the Storm Doris weather warning and their response to it. 
In keeping with previous studies in the United Kingdom (Lefevre et al. 2015) and elsewhere (Kox et al. 2015; LeClerc and Joslyn 2015; Morss et al. 2016; Sherman-Morris 2005), we found that those reporting greater institutional trust in the Met Office were more likely to indicate that they would undertake protective response to future warnings. It is worth noting that in the final regression model with all other variables controlled for, only trust in the Met Office as an institution (vs trust in the forecast information itself) was significantly associated with anticipated response. This suggests that the relationship between organizational trust and behavioral response goes beyond confidence in warning accuracy.

While previous negative experience of strong winds was not linked to greater perceived risk, we did find that it was positively associated with both recalled and anticipated response. This is in line with the broader risk research literature, which has linked negative risk experience to greater risk preparedness (Wachinger et al. 2013).

Strikingly, we did not find any link at all between local warning level and either recalled or anticipated response. As our sample size was large enough to detect small effects, this is unlikely to be due to a lack of statistical power. One possibility is that responses were influenced by the regional-level warnings (amber across the United Kingdom) rather than local-level warnings illustrated on the map. However, this would not account for the fact that local warning level was associated with anticipated risk and forecast trustworthiness. Another possibility is that the existence of a warning as opposed to warning level affects whether a behavioral response is undertaken. If this is the case, then it could suggest that responses to wind warnings may not be sensitive to differences in warning level, at least with respect to yellow and amber. However, as the nature of the Storm Doris event meant that a "no warning" control group was impossible (i.e., because all areas of the United Kingdom have some form of regional-level warning in places), we cannot conclusively confirm whether this is the case. If it is, however, then it has important implications for weather warning delivery in the United Kingdom, as it could suggest that protective responses do not become more likely as warning levels increase. Further research is therefore needed to assess whether this is the case for other types of severe weather event and how responses to yellow and amber warnings compare to those for red warnings and "no warning" controls.

In summary, our findings show that protective response is consistently linked to negative experience and concern (associated with perceived vulnerability), and that trust in the Met Office has an important link with behavioral intention. However, we do not find any effect of local warning level on recalled or anticipated response, potentially indicating that a switch from yellow to amber does not necessarily increase the likelihood of protective response.

\section{f. Limitations}

As with all postevent surveys our study has limitations. First, in examining behavioral response to the Storm Doris warning among a large sample we are reliant on self-report measures of what people did rather than direct observations. However, even if there had been time to construct a behavioral observation study in the interim between the Storm Doris warning first being issued and its impacts being realized it would not have been feasible to acquire observations from a sample of this size. It does, however, suggest an important role for further econometric evaluations in assessing the realized benefits (economic and health) of weather warnings. Second, isolated postevent surveys capture responses at one point in time, meaning that they cannot detect changes in weather warning response behavior. With meteorological services often updating weather warning delivery, this highlights the value of continually assessing public interpretation and response. Third, while the items used to assess comprehension of impact-based forecasts highlight where misinterpretations may occur, further qualitative work would be useful to gaining a more detailed understanding of forecast interpretation. Last, in eliciting measures of anticipated risk we presented participants with information about the color-coded warning level for their local area, but did not present accompanying impact matrices. Given Mu et al.'s (2018) finding that matrices increased focus on likelihood (vs severity) in a student sample, future work should establish how they affect perception and action among broader public samples.

\section{Conclusions and implications}

This study has five important implications for U.K. weather warning communication. First, the public tends to correctly link impact-based warnings to the consequences of severe weather but is less aware that these are locally calibrated. This indicates a need for education to avoid people underestimating the level of local risk indicated by severe weather warnings because they believe their local area to be more resilient to specific events than other regions of the United Kingdom. Second, local warning levels do not tend to be underestimated, but they may be overestimated 
when warning maps are presented alongside regionallevel warnings. In some cases this may reflect appropriate uncertainty about the boundaries of warning areas. However, in others it suggests that people either do not consult the map or are unable to identify their map location. Our findings support the Met Office's decision to provide website users with options to identify their specific location on the warning map. Third, as in other risk contexts, institutional trust in warning providers has a critical link with expectations about the threat posed by severe weather events and behavioral intentions. Moreover, perceived trustworthiness of specific forecasts is perceived to be higher when warnings are perceived as easy to understand. This demonstrates the critical importance of building and maintaining trust in weather warning providers and ensuring that warning information is perceived as easy to understand. Fourth, intention to undertake a protective response is most strongly linked with concern about the event, which is related to perceived vulnerability. Identifying effective communication strategies to address cases where perceived vulnerability and concern are inconsistent with assessed level of risk, should thus be a focus of further research. Fifth, we have found that behavioral response to severe wind warnings may not be sensitive to gradations of warning level, or at least the distinction between yellow and amber, although the nature of Storm Doris does not provide us with either a "no warning" control or a "red warning" comparison. This highlights the need for further experimental and postevent studies to further explore whether this apparent lack of sensitivity to warning levels is present for other types of weather event. Above all, this study demonstrates the importance of conducting country-specific research to examine how the public interpret and respond to severe weather warnings.

Acknowledgments. This research has been supported by Leeds University Business School. We thank the World Meteorological Organization's High Impact Weather (HIWeather) initiative for facilitating this collaboration.

\section{REFERENCES}

Ash, K. D., R. L. Schumann III, and G. C. Bowser, 2014: Tornado warning trade-offs: Evaluating choices for visually communicating risk. Wea. Climate Soc., 6, 104-118, https://doi.org/ 10.1175/WCAS-D-13-00021.1.

BBC, 2017a: Weather warnings explained. Accessed 14 October 2018, https://www.bbc.co.uk/weather/features/16857847.

_ 2017b: Storm Doris: Woman killed as UK hit by winds reaching $94 \mathrm{mph}$. Accessed 14 April 2019, https://www.bbc.co.uk/ news/uk-39060095.
Cao, Y., B. J. Boruff, and I. M. McNeill, 2016: Is a picture worth a thousand words? Evaluating the effectiveness of maps for delivering wildfire warning information. Int. J. Disaster Risk Reduct., 19, 179-196, https://doi.org/10.1016/j.ijdrr.2016.08.012.

Casteel, M. A., 2016: Communicating increased risk: An empirical investigation of the national weather service's impact-based warnings. Wea. Climate Soc., 8, 219-232, https://doi.org/ 10.1175/WCAS-D-15-0044.1.

_, 2018: An empirical assessment of impact-based tornado warnings on shelter in place decisions. Int. J. Disaster Risk Reduct., 30, 25-33, https://doi.org/10.1016/j.ijdrr.2018.01.036.

__ , and J. R. Downing, 2013: How individuals process NWS weather warning messages on their cell phones. Wea. Climate Soc., 5, 254-265, https://doi.org/10.1175/WCAS-D-1200031.1.

Comstock, R. D., and S. Mallonee, 2005: Comparing reactions to two severe tornadoes in one Oklahoma community. Disasters, 29, 277-287, https://doi.org/10.1111/j.0361-3666.2005.00291.x.

Dillon, R. L., C. H. Tinsley, and M. Cronin, 2011: Why near-miss events can decrease an individual's protective response to hurricanes. Risk Anal., 31, 440-449, https://doi.org/10.1111/ j.1539-6924.2010.01506.x.

Donner, W. R., H. Rodriguez, and W. Diaz, 2012: Tornado warnings in three southern states: A qualitative analysis of public response patterns. J. Homeland Secur. Emerg. Manag., 9, https://doi.org/10.1515/1547-7355.1955.

Earle, T. C., and G. Cvetkovich, 1995: Social Trust: Toward a Cosmopolitan Society. Greenwood Publishing Group, 220 pp.

Finucane, M. L., A. Alhakami, P. Slovic, and S. M. Johnson, 2000: The affect heuristic in judgments of risks and benefits. J. Behav. Decis. Making, 13, 1-17, https://doi.org/10.1002/(SICI)10990771(200001/03)13:1<1::AID-BDM333>3.0.CO;2-S.

Goldstraw, C., 2012: The public weather service customer group. Weather, 67, 128-131, https://doi.org/10.1002/wea.1884.

Harries, T., 2008: Feeling secure or being secure? Why it can seem better not to protect yourself against a natural hazard. Health Risk Soc., 10, 479-490, https://doi.org/10.1080/ 13698570802381162.

, 2012: The anticipated emotional consequences of adaptive behaviour-Impacts on the take-up of household floodprotection measures. Environ. Plann., 44A, 649-668, https:// doi.org/10.1068/a43612.

Huang, S.-K., M. K. Lindell, and C. S. Prater, 2016: Who leaves and who stays? A review and statistical meta-analysis of hurricane evacuation studies. Environ. Behav., 48, 991-1029, https:// doi.org/10.1177/0013916515578485.

Jon, I., S.-K. Huang, and M. K. Lindell, 2018: Perceptions and reactions to tornado warning polygons: Would a gradient polygon be useful? Int. J. Disaster Risk Reduct., 30, 132-144, https://doi.org/10.1016/j.ijdrr.2018.01.035.

,-- , and -2019 : Perceptions and expected immediate reactions to severe storm displays. Risk Anal., 39, 274-290, https://doi.org/10.1111/risa.12896.

Kim, M., H. Kim, and M. You, 2014: The role of public awareness in health-protective behaviours to reduce heat wave risk. Meteor. Appl., 21, 867-872, https://doi.org/10.1002/met.1422.

Kox, T., and A. H. Thieken, 2017: To act or not to act? Factors influencing the general public's decision about whether to take protective action against severe weather. Wea. Climate Soc., 9, 299-315, https://doi.org/10.1175/WCAS-D-15-0078.1.

, L. Gerhold, and U. Ulbrich, 2015: Perception and use of uncertainty in severe weather warnings by emergency services in Germany. Atmos. Res., 158, 292-301, https://doi.org/ 10.1016/j.atmosres.2014.02.024. 
LeClerc, J., and S. Joslyn, 2015: The cry wolf effect and weatherrelated decision making. Risk Anal., 35, 385-395, https:// doi.org/10.1111/risa.12336.

Lefevre, C. E., W. B. de Bruin, A. L. Taylor, S. Dessai, S. Kovats, and B. Fischhoff, 2015: Heat protection behaviors and positive affect about heat during the 2013 heat wave in the United Kingdom. Soc. Sci. Med., 128, 282-289, https://doi.org/10.1016/ j.socscimed.2015.01.029.

Lindell, M. K., and R. W. Perry, 2012: The protective action decision model: Theoretical modifications and additional evidence. Risk Anal., 32, 616-632, https://doi.org/10.1111/ j.1539-6924.2011.01647.x.

— , S.-K. Huang, H.-L. Wei, and C. D. Samuelson, 2016: Perceptions and expected immediate reactions to tornado warning polygons. Nat. Hazards, 80, 683-707, https://doi.org/ 10.1007/s11069-015-1990-5.

Lorenz, S., S. Dessai, P. M. Forster, and J. Paavola, 2015: Tailoring the visual communication of climate projections for local adaptation practitioners in Germany and the UK. Philos. Trans. Roy. Soc., 373A, 20140457, https://doi.org/ 10.1098/rsta.2014.0457.

Losee, J. E., and S. Joslyn, 2018: The need to trust: How features of the forecasted weather influence forecast trust. Int. J. Disaster Risk Reduct., 30, 95-104, https://doi.org/10.1016/ j.ijdrr.2018.02.032.

Met Office, 2017a: Storm Doris. Accessed 14 April 2019, https:// www.metoffice.gov.uk/weather/warnings-and-advice/uk-stormcentre/storm-doris.

__ 2017b: UK storm season 2016/17. Accessed 14 April 2019, https:/www.metoffice.gov.uk/weather/warnings-and-advice/ uk-storm-centre/uk-storm-season-2016-17.

_ 2018: Weather warnings guide. Accessed 14 October 2018, https://www.metoffice.gov.uk/guide/weather/warnings.

Miran, S. M., C. Ling, J. J. James, A. Gerard, and L. Rothfusz, 2017: User perception and interpretation of tornado probabilistic hazard information: Comparison of four graphical designs. Appl. Ergon., 65, 277-285, https://doi.org/10.1016/ j.apergo.2017.06.016.

Morss, R. E., J. L. Demuth, and J. K. Lazo, 2008: Communicating uncertainty in weather forecasts: A survey of the U.S. public. Wea. Forecasting, 23, 974-991, https://doi.org/ 10.1175/2008WAF2007088.1.

_ K. J. Mulder, J. K. Lazo, and J. L. Demuth, 2016: How do people perceive, understand, and anticipate responding to flash flood risks and warnings? Results from a public survey in Boulder, Colorado, USA. J. Hydrol., 541, 649-664, https:// doi.org/10.1016/j.jhydrol.2015.11.047.

, C. L. Cuite, J. L. Demuth, W. K. Hallman, and R. L. Shwom, 2018: Is storm surge scary? The influence of hazard, impact, and fear-based messages and individual differences on responses to hurricane risks in the USA. Int. J. Disaster Risk Reduct., 30, 44-58, https://doi.org/ 10.1016/j.ijdrr.2018.01.023.

Mu, D., T. R. Kaplan, and R. Dankers, 2018: Decision making with risk-based weather warnings. Int. J. Disaster Risk Reduct., 30, 59-76, https://doi.org/10.1016/j.ijdrr.2018.03.030.

Nagele, D. E., and J. E. Trainor, 2012: Geographic specificity, tornadoes, and protective action. Wea. Climate Soc., 4, 145155, https://doi.org/10.1175/WCAS-D-11-00047.1.

Parker, D. J., S. J. Priest, and S. McCarthy, 2011: Surface water flood warnings requirements and potential in England and Wales. Appl. Geogr., 31, 891-900, https://doi.org/10.1016/ j.apgeog.2011.01.002.
Paul, B. K., M. Stimers, and M. Caldas, 2015: Predictors of compliance with tornado warnings issued in Joplin, Missouri, in 2011. Disasters, 39, 108-124, https://doi.org/10.1111/disa.12087.

Peachey, J. A., D. M. Schultz, R. Morss, P. J. Roebber, and R. Wood, 2013: How forecasts expressing uncertainty are perceived by UK students. Weather, 68, 176-181, https:// doi.org/10.1002/wea.2094.

Potter, S. H., P. V. Kreft, P. Milojev, C. Noble, B. Montz, A. Dhellemmes, R. J. Woods, and S. Gauden-Inge, 2018: The influence of impact-based severe weather warnings on risk perceptions and intended protective actions. Int. J. Disaster Risk Reduct., 30, 34-43, https://doi.org/10.1016/j.ijdrr.2018.03.031.

Ripberger, J. T., C. L. Silva, H. C. Jenkins-Smith, and M. James, 2015a: The influence of consequence-based messages on public responses to tornado warnings. Bull. Amer. Meteor. Soc., 96, 577-590, https://doi.org/10.1175/BAMS-D-13-00213.1.

,,--- D. E. Carlson, M. James, and K. G. Herron, 2015b: False alarms and missed events: The impact and origins of perceived inaccuracy in tornado warning systems. Risk Anal., 35, 44-56, https://doi.org/10.1111/risa.12262.

Schumann, R. L., III, K. D. Ash, and G. C. Bowser, 2018: Tornado warning perception and response: Integrating the roles of visual design, demographics, and hazard experience. Risk Anal., 38, 311-332, https://doi.org/10.1111/risa.12837.

Sherman-Morris, K., 2005: Tornadoes, television and trust-A closer look at the influence of the local weathercaster during severe weather. Global Environ. Change, 6B, 201-210, https:// doi.org/10.1016/j.hazards.2006.10.002.

_ 2013: The public response to hazardous weather events: 25 years of research. Geogr. Compass, 7, 669-685, https://doi.org/ 10.1111/gec3.12076.

Siegrist, M., and G. Cvetkovich, 2000: Perception of hazards: The role of social trust and knowledge. Risk Anal., 20, 713-720, https://doi.org/10.1111/0272-4332.205064.

Silver, A., 2015: Watch or warning? Perceptions, preferences, and usage of forecast information by members of the Canadian public. Meteor. Appl., 22, 248-255, https://doi.org/10.1002/ met.1452.

_ perience and sociodemographics on protective behaviors during two successive tornado events. Wea. Climate Soc., 6, 91-103, https://doi.org/10.1175/WCAS-D-13-00026.1.

Spiegelhalter, D. J., and H. Riesch, 2011: Don't know, can't know: Embracing deeper uncertainties when analysing risks. Philos. Trans. Roy. Soc., 369A, 4730-4750, https://doi.org/10.1098/ rsta.2011.0163.

Stewart, A. E., 2009: Minding the weather: The measurement of weather salience. Bull. Amer. Meteor. Soc., 90, 1833-1841, https://doi.org/10.1175/2009BAMS2794.1.

— J. K. Lazo, R. E. Morss, and J. L. Demuth, 2012: The relationship of weather salience with the perceptions and uses of weather information in a nationwide sample of the United States. Wea. Climate Soc., 4, 172-189, https://doi.org/10.1175/ WCAS-D-11-00033.1.

Sunstein, C. R., 2003: Terrorism and probability neglect. J. Risk Uncertain., 26, 121-136, https://doi.org/10.1023/A: 1024111006336.

Tang, C., and G. Rundblad, 2015: The potential impact of directionality, colour perceptions and cultural associations on disaster messages during heatwaves in the UK. PLoS Curr., 7, https:// doi.org/10.1371/currents.dis.775c310222d5829cb29b7a414370ca50.

Taylor, A. L., S. Dessai, and W. Bruine de Bruin, 2015: Communicating uncertainty in seasonal and interannual climate 
forecasts in Europe. Philos. Trans. Roy. Soc., 373A, 20140454 https://doi.org/10.1098/rsta.2014.0454.

,-- , and - 2017: Public priorities and expectations of climate change impacts in the United Kingdom. J. Risk Res. 22, 150-160, https://doi.org/10.1080/13669877.2017.1351479.

Trim, L., and I. Ashe, 2018: What does a yellow weather warning mean? Met Office weather warnings explained. Leicester Mercury, accessed 14 October 2018, https://www.leicestermercury.co.uk/ news/uk-world-news/what-is-a-weather-warning-1279777.

Wachinger, G., O. Renn, C. Begg, and C. Kuhlicke, 2013: The risk perception paradox-Implications for governance and communication of natural hazards. Risk Anal., 33, 1049-1065, https://doi.org/10.1111/j.1539-6924.2012.01942.x.

Weinstein, N. D., 1989: Effects of personal experience on selfprotective behavior. Psychol. Bull., 105, 31-50, https://doi.org/ 10.1037/0033-2909.105.1.31.

Weyrich, P., A. Scolobig, D. N. Bresch, and A. Patt, 2018: Effects of impact-based warnings and behavioral recommendations for extreme weather events. Wea. Climate Soc., 10, 781-796, https://doi.org/10.1175/WCAS-D-18-0038.1.

White, S., 2017: Storm Doris set to cost $£ 400$ million after a day of chaos and tragedy which left one dead. Mirror, accessed 14 April 2019, https://www.mirror.co.uk/news/uk-news/stormdoris-set-cost-400million-9911533.

Williams, C. A., P. W. Miller, A. W. Black, and J. A. Knox, 2017: Throwing caution to the wind: National Weather Service wind products as perceived by a weather-salient sample. J. Oper. Meteor., 5, 103-120, https://doi.org/10.15191/nwajom.2017.0509.

WMO, 2015: WMO guidelines on multi-hazard impact-based forecast and warning services. WMO-No. 1150, 23 pp., https:// www.wmo.int/pages/prog/www/DPFS/Meetings/ET-OWFPS_ Montreal2016/documents/WMOGuidelinesonMulti-hazardImpactbasedForecastandWarningServices.pdf.

Wong, T., and Y. Yan, 2002: Perceptions of severe weather warnings in Hong Kong. Meteor. Appl., 9, 377-382, https://doi.org/ $10.1017 / \mathrm{S} 1350482702003110$. 